\title{
The outcome for surgical fixation of distal radial fractures in patients with idiopathic Parkinson's disease: a cohort study
}

Te-Feng Arthur Chou ${ }^{1,2}$, Chun Yao Chang ${ }^{1}$, Chun-Ching Huang ${ }^{1,3}$, Ming-Chau Chang ${ }^{1,2}$, Wei-Ming Chen ${ }^{1,2}$ and Tung-Fu Huang ${ }^{1,2,3^{*}}$

\begin{abstract}
Introduction: Idiopathic Parkinson's disease (PD) is a progressive neurologic disorder causing postural instability and unsteady gait. These patients are at increased risk for fractures and have inferior outcomes after treatment. Several studies have evaluated the incidence and outcome of PD patients after hip fractures. However, there are limited studies assessing the outcome of upper extremity fractures in these patients. In this study, we evaluated the outcome of PD patients that received surgical intervention for distal radial fractures (DRF). We hypothesize that these patients have an inferior outcome after surgery in comparison with non-PD patients.

Methods: Between May 2005 and May 2017, we retrospectively reviewed all of the patients with DRF and subsequently underwent open reduction and internal fixation (ORIF) at a level 1 trauma center. All of the surgeries were performed by fellowship-trained orthopedic surgeons. The inclusion criteria include patients with a definitive diagnosis of PD, non-pathological DRF, and a minimum follow-up of 1 year or up until the time of treatment failure was noted. Each PD patient was matched for age and gender to 3 non-PD patients. The primary objective was to determine the failure rate after surgical fixation for DRF. The secondary outcomes include time to treatment failure, reoperation rate, readmission rate, length of hospital stay, and postoperative complications.

Results: A total of 88 patients were included in this study (23 PD, 65 non-PD patients). All underwent ORIF and received standard postoperative follow-ups. The overall treatment failure rate in PD was $39.1 \%$ vs. $4.6 \%$ in the nonPD group $(p<0.05)$. The time to treatment failure were $9.11 \pm 3.86$ weeks and $14.67 \pm 5.8$ weeks for PD and nonPD, respectively $(p<0.05)$. PD patients had a significantly higher rate of failure when k-wires and ESF were used ( $p$ $<0.05 \%$ ), while loss of reduction was the most common mode of failure in PD (44.4\%). The length of hospital stay for PD was $5.3 \pm 4.69$ days compared with $3.78 \pm 0.96$ days for non-PD $(p=0.01)$. There were 3 PD patients readmitted within 30 days after surgery, and 1 patient had pneumonia after the surgery.

(Continued on next page)
\end{abstract}

\footnotetext{
* Correspondence: Tungfu.huang@gmail.com

${ }^{1}$ Department of Orthopaedics and Traumatology, Taipei Veterans General Hospital, No. 201, Sec. 2, Shi-Pai Road, Taipei 112, Taiwan, Republic of China ${ }^{2}$ Department of Orthopaedics, School of Medicine, National Yang-Ming University, No. 201, Sec. 2, Shi-pai Road, Beitou District, Taipei City 11217, Taiwan, ROC

Full list of author information is available at the end of the article
}

C C The Author(s). 2020 Open Access This article is licensed under a Creative Commons Attribution 4.0 International License, which permits use, sharing, adaptation, distribution and reproduction in any medium or format, as long as you give appropriate credit to the original author(s) and the source, provide a link to the Creative Commons licence, and indicate if changes were made. The images or other third party material in this article are included in the article's Creative Commons licence, unless indicated otherwise in a credit line to the material. If material is not included in the article's Creative Commons licence and your intended use is not permitted by statutory regulation or exceeds the permitted use, you will need to obtain permission directly from the copyright holder. To view a copy of this licence, visit http://creativecommons.org/licenses/by/4.0/. The Creative Commons Public Domain Dedication waiver (http://creativecommons.org/publicdomain/zero/1.0/) applies to the data made available in this article, unless otherwise stated in a credit line to the data. 


\begin{abstract}
(Continued from previous page)
Conclusion: This study revealed that patients with PD have a high treatment failure rate despite surgical

intervention for DRF. PD patients had a longer hospital stay and had a shorter time to treatment failure. In treating

PD patients complicated with DRF, the surgeon must take into consideration the complex disease course of PD and

the associated comorbidities such as osteoporosis, frail status, and frequent falls. Rehabilitation and disposition plans

should be discussed in advance and longer hospital stays should be expected.

Level of evidenceLevel IV, retrospective cohort study
\end{abstract}

Keywords: Parkinson's disease, Distal radial fractures, Osteoporosis, Fracture nonunion

\section{Introduction}

Idiopathic Parkinson's disease (PD) is a chronic, progressive neurologic disorder characterized by rigidity, postural instability, and unsteady gait, leading to an increased risk for falls [1]. It is estimated that $70-87 \%$ of PD patients that are treated for longer than 20 years will have a fall injury [1]. In addition, it is estimated that these patients have almost two-folds of risk for fractures compared with the general population. The increased risk can be attributed to several factors. First, PD patients are at increased risks for falls and $90 \%$ of fractures in the elderly are directly related to falls [2]. Additional factors including advanced age, multiple comorbidities, and osteoporosis place PD patients at a significantly higher rate of fractures as well as postoperative complications [3]. On the other hand, several medication side effects also predispose PD patients to fractures. In particular, commonly used drugs such as monoamine oxidase-B (MAO-B) inhibitors, selective serotonin receptor inhibitors (SSRI), and high-dose antipsychotics all significantly increase the risk of osteoporotic fractures [4]. Therefore, it is essential for the physician to identify PD amongst this population in order to provide the appropriate care.

Of all types of fractures, the hip, forearm, and vertebrae are the most commonly affected sites [4]. Several studies have evaluated the outcome of PD patients after hip fractures [3]. Most of the literature suggests that PD is an independent risk factor for inferior outcomes after a hip fracture with increased risks for mortality, reoperation, surgical complications, and reduced mobility $[5,6]$. Although hip fractures have been frequently discussed, limited studies have assessed the outcome of upper extremity fractures in PD patients. In particular, the distal radial fracture (DRF) is the second most common fracture observed in this population [4]. Since PD most often occurs in elderly patients, it can be intuitive to treat these patients with similar treatment methods as the elderly population. However, the appropriate treatment option for elderly patients that sustained a DRF remains controversial. The most recent American Academy of Orthopaedic Surgeons (AAOS) clinical practice guideline was unable to recommend for or against the treatment of distal radial fractures in elderly patients $[7,8]$. If treated nonoperatively, the malunion rate can be as high as 89\% [9]. For patients that received surgical intervention, poor wound healing, anesthesia related risks, and iatrogenic injuries are all concerns when treating the elderly [7]. With the significantly inferior outcome in the elderly, a comprehensive review to evaluate the outcome for DRF in PD is essential. In this study, we evaluated the outcome of PD patients that received surgical intervention for DRF and compared them with elderly patients without PD. We hypothesize PD patients who sustained DRF will have inferior outcomes compared with non-PD patients.

\section{Methods}

This was a retrospective cohort study performed at a level 1 trauma center in Taipei, Taiwan. The study was approved by our hospital's institutional review board. The primary outcome of the study was to determine the treatment failure rate of PD patients after surgical intervention for DRF. The secondary outcome was to determine the time to treatment failure, associated injuries, reoperation rate, length of hospital stay, readmission rate within 30 days, and postoperative complications (eg., pneumonia, UTI, delayed wound healing).

\section{Study population}

The inclusion criteria were as follows: patients that underwent surgical fixation for a DRF with either fracture type $\mathrm{A}, \mathrm{B}$, or $\mathrm{C}$ by the OTA/AO classification system, patients that were 18 years old or older and were able to tolerate anesthesia, and had a minimum follow-up for 1 year or up to the time where treatment failure was noted. We excluded patients that declined surgery, under 18 years of age, and open or complex pathological fractures. The patients were allocated to either the PD group or to the nonPD group according to their diagnosis. A diagnosis of PD was made based on clinical history, review of medical records (ICD-9 CM code 332.0), and identifying PD-related drugs in the prescription records (levodopa-carbidopa, dopamine agonists, monoamine oxidase B inhibitors, 
catechol-O-methyltransferase inhibitors). A patient was assigned to the PD group if one of the above criteria for $\mathrm{PD}$ was met. If the patient did not meet our criteria, he/ she was assigned to non-PD.

\section{Surgical intervention and patient assessment}

All of the included patients underwent surgical reduction and fixation, either with plates, k-wires, external fixator (ESF), or a combination of the above methods. All of the surgeries were performed by fellowshiptrained orthopedic surgeons. The choice of fixation method was determined based on the fracture pattern and the surgeon's preference. All of the patients received a standard perioperative protocol. The medical records were comprehensively reviewed for pertinent histories such as American Society of Anesthesiologist physical status (ASA) grade, history of coronary artery disease (CAD), diabetes mellitus (DM), chronic kidney disease (CKD), osteoporosis, and smoking status. We evaluated each patient at 2 weeks, 1 month, 3 months, and 12 months after the surgery. If treatment failure was noted prior to the final follow-up, the follow-up duration was recorded as the time of treatment failure. Standard posteroanterior and lateral radiographs were obtained immediately after the surgery and at each visit. At each visit, we assessed the patient's pain score with the visual analog scale (VAS). For radiographic assessment, we measured the radial inclination, articular step-off and palmar tilt for each visit. Treatment failure was considered if there was a loss of reduction, malunion or nonunion of the fracture. A loss of reduction is defined as a change in reduction in comparison to the immediate postop $x$-rays, including radial inclination $>5^{\circ}$ of change, articular step-off $>2 \mathrm{~mm}$, and palmar tilt $>5^{\circ}$ of change. A malunion was defined as persistent pain upon activity (VAS > 5) 3 months after the surgery and/or limited radiographic evidence of fracture healing 6 months postoperatively. All measurements and assessments were completed by two senior orthopedic surgeons.

\section{Pilot study and patient population size}

A pilot study consisting of 40 patients (20 patients in each group) was first completed to determine the ideal sample size required to achieve an alpha level of 0.05 with $80 \%$ power. The failure rate noted in the PD group and non-PD group were $35 \%$ and $3 \%$ respectively. We then matched our patients in a 1:3 ratio (PD:non-PD) for age and gender. These results indicate that a study consisting of at least 44 patients (12 patients:36 patients) was required to achieve statistical significance.

\section{Statistical analysis}

All data were entered and analyzed with the SPSS software (version 25.0, SPSS Inc., Chicago, IL). We recorded data as mean, range, and standard deviation for continuous variables and the student's $t$ test was used to compare the differences at appropriate times. For categorical data such as percentages, we used the fisher's exact test when the patient sample size was less than or equal to 5 , and the chi-square test when the patient sample size was greater than 5 to assess for statistical significance. A $p$ value $<0.05$ and confidence interval $>95 \%$ were considered to be statistically significant.

\section{Results}

After excluding the patients that did not meet the inclusion criteria, we enrolled a total of 88 patients in this study. There were 23 patients that had PD (mean disease duration $16.3 \pm 2.1$ months) with DRF and 65 non-PD patients with DRF. The mean follow-up duration was $8.83 \pm 12.52$ months.

\section{Baseline characteristics}

The mean age was $75.7 \pm 6.96$ and $71.1 \pm 8.81$ years in the PD and non-PD group respectively $(p=0.11)$. The percentage of female patients were $73.9 \%$ in the PD group and $75.4 \%$ in the non-PD group $(p=0.89)$. The mean age, gender ratio, ASA grade, incidence of smoking, CAD, DM, and CKD were similar in both groups (Table 1). However, there was a significant difference in the fracture pattern between the groups. There was a significantly higher proportion of type $\mathrm{C}$ fractures (47.8\% vs. 27.7\%; PD:non-PD) for the PD patients, while there was a higher trend for type $\mathrm{B}$ fractures $(4.3 \%$ vs. 27.7\%; PD:non-PD) in the non-PD patients $(p<0.14)$. The baseline characteristics are shown in Table 1.

\section{Surgical method and outcome}

The surgical method and outcome for both groups are shown in Table 2. The patients in PD had a higher percentage of k-wire fixation ( $26.1 \%$ vs. $6.2 \%)$, while a higher rate of plating was noted for the non-PD patients $(56.5 \%$ vs. $78.5 \%),(p<0.05)$. A total of $39.1 \%$ of the patients in the PD group had treatment failure at a mean follow-up of $6.57 \pm 6.6$ months, while the failure rate was $4.6 \%$ in non-PD at mean follow up of $9.63 \pm 14.0(p<0.05)$. Two failure cases are presented in Figs. 1 and 2. In terms of choice of fixation, PD patients had a significantly higher rate of failure when k-wires and ESF were used $(p<$ $0.05 \%$ ), while plating of DRF appeared to have similar results between the two groups (Table 3). As for modes of failure, PD patients were more likely to have a loss of reduction and nonunion of fracture $(17.4 \%$ and $13 \%$ vs. $1.5 \%$ and $1.5 \%$ for PD vs. non-PD respectively, $p<0.05$ ). The length of hospital stay was $5.3 \pm 4.69$ days for PD and 3.78 \pm 0.96 days for non-PD $(p=0.01)$. There was one PD patient who had a reoperation within 30 days due to screw penetration which required removal of internal fixation. 
Table 1 Patient characteristics

\begin{tabular}{|c|c|c|c|c|}
\hline & Overall & Patients w/ PD $(n=23)$ & Patients w/o PD $(n=65)$ & $p$ value \\
\hline Age (years) & $72.35 \pm 8.57$ & $75.7 \pm 6.96$ & $71.1 \pm 8.81$ & 0.11 \\
\hline Female patients (\%) & $66(75.0 \%)$ & $17(73.9 \%)$ & 49 (75.4\%) & 0.89 \\
\hline \multicolumn{5}{|l|}{ Fracture type (AO/OTA)* } \\
\hline Type A & $40(45.5 \%)$ & $11(47.8 \%)$ & $29(44.6 \%)$ & 0.41 \\
\hline Type B & $19(21.6 \%)$ & $1(4.3 \%)$ & 18 (27.7\%) & 0.14 \\
\hline Type C & $29(33.0 \%)$ & $11(47.8 \%)$ & $18(27.7 \%)$ & 0.67 \\
\hline ASA grade & & & & 0.78 \\
\hline Class I/II & $9(10.2 \%)$ & $2(8.7 \%)$ & $7(10.8 \%)$ & \\
\hline Class III/IV & 79 (89.8\%) & $21(91.3 \%)$ & $58(89.2 \%)$ & \\
\hline Smoking history & $16(18.2 \%)$ & $5(21.7 \%)$ & $11(16.9 \%)$ & 0.61 \\
\hline \multicolumn{5}{|l|}{ Comorbidities } \\
\hline$C A D$ & 13 & 3 & 10 & 0.54 \\
\hline DM & 17 & 2 & 15 & 0.11 \\
\hline CKD & 10 & 3 & 7 & 0.52 \\
\hline Osteoporosis & 20 & 9 & 11 & 0.03 \\
\hline PD duration (months) & $x$ & $16.3 \pm 2.1$ & $x$ & $x$ \\
\hline Follow-up duration (months) & $8.83 \pm 12.52$ & $6.57 \pm 6.56$ & $9.63 \pm 14.0$ & 0.18 \\
\hline
\end{tabular}

*Fracture type was assessed using the AO/OTA classification 2007

ASA American Society of Anesthesiologist physical status classification system 2014, PD Parkinson's disease, CAD coronary artery disease, DM diabetes mellitus, CKD chronic kidney disease

Table 2 Perioperative data

\begin{tabular}{|c|c|c|c|c|}
\hline & Overall & Patients w/ PD & Patients w/o PD & $p$ value \\
\hline Number of patients & 88 & 23 & 65 & \\
\hline \multicolumn{5}{|l|}{ Surgical intervention } \\
\hline K-wires & $10(11.4 \%)$ & $6(26.1 \%)$ & $4(6.2 \%)$ & $<0.05$ \\
\hline External Fixation & $14(15.9 \%)$ & $4(17.4 \%)$ & $10(15.4 \%)$ & 0.53 \\
\hline Plates & $63(72.7 \%)$ & $13(56.5 \%)$ & $51(78.5 \%)$ & $<0.05$ \\
\hline Outcome & & & & $<0.05$ \\
\hline Union & 76 (86.4\%) & $14(60.9 \%)$ & $62(95.4 \%)$ & \\
\hline Treatment failure & $12(13.6 \%)$ & 9 (39.1\%) & $3(4.6 \%)$ & \\
\hline Associated injuries & $6(6.8 \%)$ & $3(13 \%)$ & $3(4.6 \%)$ & 0.17 \\
\hline Reoperation & $1(1.1 \%)$ & $1(4.3 \%)^{*}$ & 0 & 0.91 \\
\hline Length of stay (days) & $4.42 \pm 2.59$ & $5.3 \pm 4.69$ & $3.78 \pm 0.96$ & 0.01 \\
\hline Readmission ( $<30$ days) & $4(4.5 \%)$ & $3(13.0 \%)$ & $1(1.5 \%)$ & 0.05 \\
\hline Complications & $2(2.2 \%)$ & $1(4.3 \%)$ & $1(1.5 \%)$ & $x$ \\
\hline Pneumonia & $1(1.1 \%)$ & $1(4.3 \%)$ & 0 & \\
\hline UTI & 0 & 0 & 0 & \\
\hline Wound & $1(1.1 \%)$ & 0 & $1(1.5 \%)$ & \\
\hline Mortality & 0 & 0 & 0 & \\
\hline Thromboembolism & 0 & 0 & 0 & \\
\hline
\end{tabular}




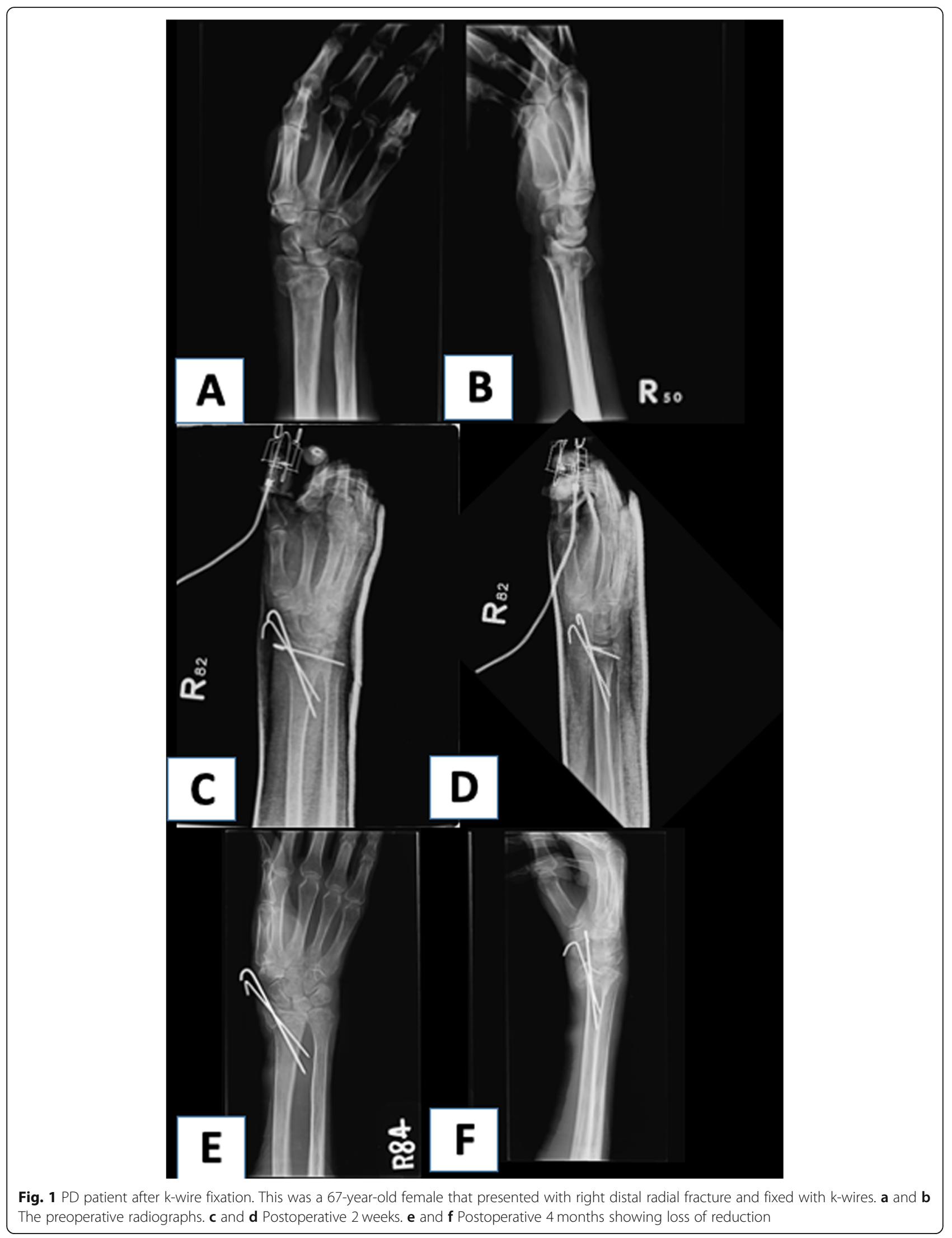




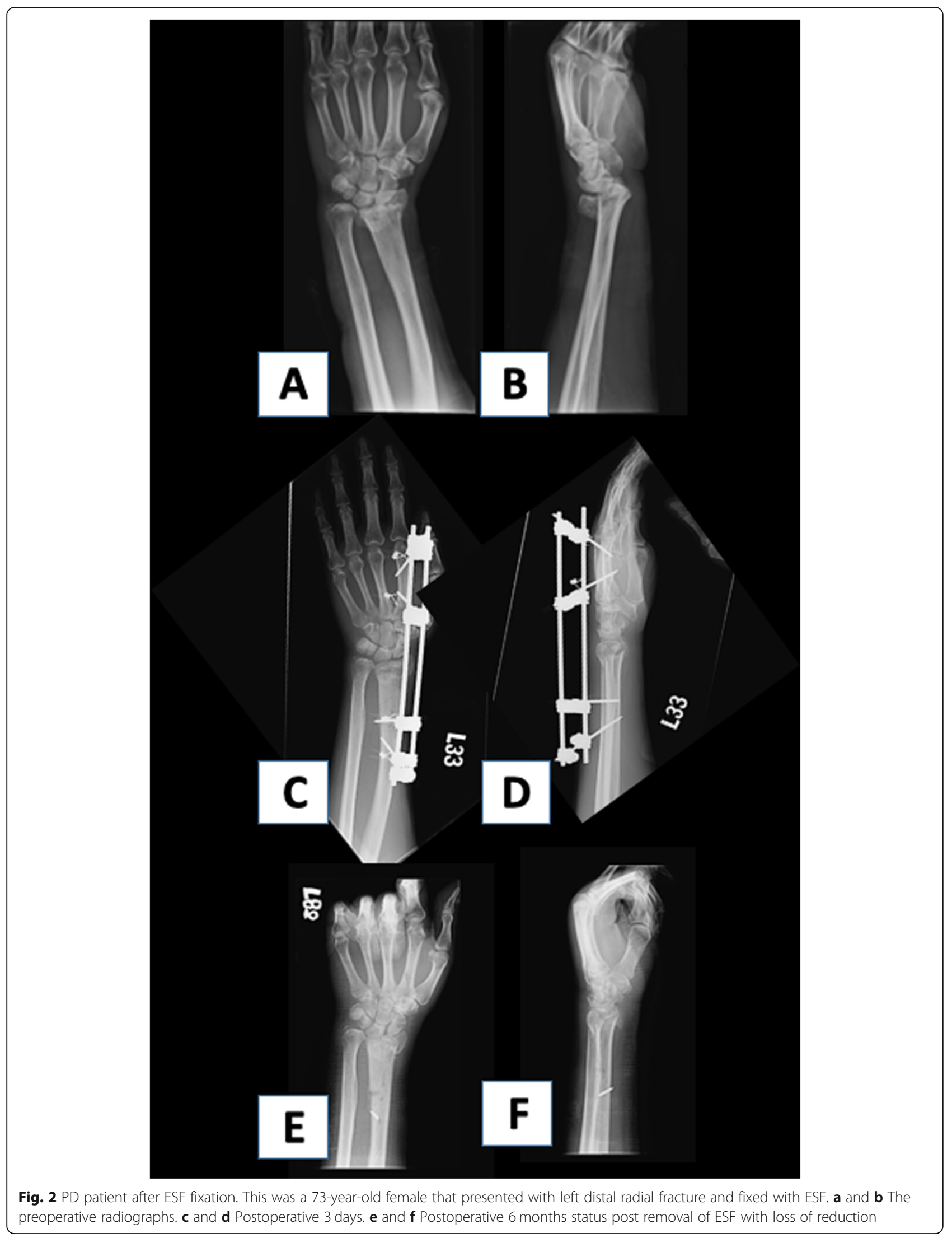


Table 3 The modes of failure and time to failure

\begin{tabular}{|c|c|c|c|c|}
\hline & Overall & Patients w/ PD & Patients w/o PD & $p$ value \\
\hline Treatment failure & 12 & 9 & 3 & $<0.001$ \\
\hline K-wires & 4 & 4 & 0 & $<0.05$ \\
\hline External fixation & 4 & 3 & 1 & $<0.05$ \\
\hline Plates & 4 & 2 & 2 & 0.28 \\
\hline Modes of failure & & & & $<0.05$ \\
\hline Loss of reduction & $5(41.6 \%)$ & $4(44.4 \%)$ & $1(33.3 \%)$ & $<0 . .05$ \\
\hline Nonunion of fracture & $4(33.3 \%)$ & $3(33.3 \%)$ & $1(33.3 \%)$ & 0.05 \\
\hline Persistent pain & $3(25 \%)$ & $2(22.2 \%)$ & $1(33.3 \%)$ & 0.28 \\
\hline Time to failure (weeks) & $10.5 \pm 4.14$ & $9.11 \pm 3.86$ & $14.67 \pm 5.8$ & $<0.05$ \\
\hline
\end{tabular}

In comparison, there were no reoperations for non-PD. In terms of 30-day readmissions, there were 3 patients from PD that were readmitted (one patient required removal of implant, another patient received treatment for postoperative pneumonia, and another patient had a second fall accident causing a hip fracture that required surgical fixation). One patient had a wound infection in non-PD which required debridement and was admitted for intravenous antibiotic treatment.

\section{Treatment failure and modes of failure}

There were $39.1 \%$ of patients $(n=9)$ that had treatment failure in PD, and $4.6 \%(n=3)$ in non-PD. The average time to treatment failure were $9.11 \pm 3.86$ weeks and $14.67 \pm 5.8$ weeks for the PD and non-PD group respectively $(p<0.05)$. The modes of failure are described in Table 3. For PD patients, loss of reduction was seen in $17.4 \%$ of patients, fracture nonunion in $13.0 \%$, and persistent pain was observed after 6 months in $8.7 \%$ of patients.

\section{Discussion}

To our knowledge, this was the first cohort study to evaluate the outcome of DRF in PD patients. The most significant finding of this study was the substantially higher failure rate noted in $\mathrm{PD}(39.1 \%$ vs. $4.6 \%$; $p<$ $0.05)$. In current literature, there are many studies that have indicated PD patients who have inferior outcomes and have increased risks for surgical complications after orthopedic procedures $[3,5,10,11]$. . Most studies have focused on hip fractures, and the outcome for DRF remains unknown.

\section{The outcome of fractures in patients with Parkinson's disease and elderly patients}

Although the majority of patients that receive surgical fixation for DRF have good to excellent outcomes, PD patients appear to have inferior results. In the general population, the nonunion rate is reported to be as low as $<1 \%$ and the overall complication rate in current literature for DRF ranges from 14 to $30 \%$ in the general population [4, 12-14]. In our study, we considered patients to have a treatment failure if there was loss of reduction, malunion or nonunion of fracture, or persistent pain at the injured site 6 months after surgery. We noted $4.6 \%$ of the non-PD patients had treatment failure, while $39.1 \%$ of the patients in the PD group were considered to have treatment failure. The cause for this substantially higher rate of treatment failure is currently unknown, but it is most likely multifactorial. For instance, PD patients often exhibit severe rigidity which may cause early failure of fixation [15]. Hence, there was a significantly higher rate of loss of reduction in the PD group. In addition, the frail status and frequent falls exhibited in this patient population may further complicate the postoperative recovery course [6]. Lastly, the frequent resting tremors observed in PD may also have altered the healing process. In order to facilitate optimal bone healing to occur, stabilizing the fracture either through relative stability or absolute stability is essential [16]. Most of the current studies for fractures in PD patients have focused on hip fractures. Roche et al. evaluated 2448 patients that sustained a hip fracture, 97 of whom had PD. Their results suggested PD was not a risk for 1-year mortality. On the other hand, several reports noted an inferior outcome for PD patients after sustaining a hip fracture with mortality rates as high as $47 \%[6,17]$. Karadsheh et al. reported $\mathrm{PD}$ as an independent predictor of mortality after operative treatment for femoral neck fractures. Interestingly, PD patients were more likely to sustain a dislocation after hemiarthroplasty and fixation failure for minimally displaced fractures [6]. The reoperation rates for $\mathrm{PD}$ were $4 \%$ and $22 \%$ for displaced femoral neck fractures and nondisplaced fractures respectively. Although the two groups received different surgical interventions, the significantly higher 
reoperation rates in the nondisplaced group prompted the authors to favor the use of hemiarthroplasties for non-displaced femoral neck fractures in PD patients.

\section{The choice of fixation method for DRF in PD patients}

Although k-wire fixation and ESF are often considered to be relatively stable fixation techniques and provide fairly good outcomes in the general population, it should be used with caution in PD. In this study, there was a higher percentage of patients undergoing k-wire or ESF fixation in $\mathrm{PD}(n=10,43.5 \%$ vs. $n=14,21.6 \%$; for $\mathrm{PD}$ and non-PD respectively). For patients that underwent k-wire fixation, 4 (66.7\%) PD patients had treatment failure while none were observed in the non-PD group $(n<$ 0.05). Meanwhile, $3(75 \%)$ patients that received ESF had treatment failure while only 1 patient in non-PD (10\%) had a treatment failure $(p<0.05)$ (Table 3$)$. The higher rate of failure is currently unknown. However, PD patients often have frequent tremors and may cause micro-instability over the fracture site and may impede proper fracture healing. In addition, the constant rigidity exhibited in these patients may also cause excessive muscle contracture, leading to displacement of the fracture fragments. In agreement with our results, we noted the most common modes of failure were loss of reduction and nonunion of fracture in PD patients. Therefore, our authors recommend a rigid fixation method such as locked plates for PD patients in order to assure proper fracture healing.

\section{Length of hospital stay and potential problems in caring PD patients}

PD patients often have multiple comorbidities which may complicate their postoperative care. Pouwels et al. identified cancer, ischemic heart disease, and cerebrovascular disease as the three most common associated comorbidities in PD patients that have sustained a fracture [4]. In this study, we noted osteoporosis to be the most commonly associated disease in a relatively small sample size, which can partly explain the higher incidence of osteoporotic fractures. In a comprehensive review of 9225 patients with hip fracture (452 patients with PD), Coomber et el. noted a significantly longer hospital stay for PD patients [3]. In-hospital complications were relatively common, of which postoperative delirium, pressure sores, pneumonia all occurred more often in patients with PD. In this study, PD patients were admitted in an acute orthopedic ward for $5.3 \pm 4.69$ days while non-PD patients had a shorter stay of $3.78 \pm 0.96$ days ( $p$ $=0.01$ ). There was one PD patient complicated with aspiration pneumonia which required extended stay for treatment. Most of the postoperative complications recorded in literature can be partly attributed to the disease nature of PD as well as medication side effects (eg., sedatives). Therefore, we routinely consult neurology and geriatric specialists to manage the postoperative course.

For patients in the non-PD group, only one patient had wound dehiscence which was treated in under local anesthesia with debridement and primary closure of the wound. This patient was subsequently admitted for intravenous antibiotics. As for 30-day readmissions, there was a significantly higher rate of readmissions for PD (13\% vs. $1.5 \%, p=0.05)$. One patient required removal of implant, another patient received treatment for postoperative pneumonia, and another patient had a hip fracture that required surgical fixation. In addition to proper management of the DRF, detailed workup for osteoporosis and fall prevention measures are essential for PD patients to reduce postoperative complications. Since the bone mineral density in patients with PD is lower compared with healthy controls, appropriate medications such as bisphosphonates and denosumab should be initiated once osteoporosis is confirmed [18].

There are several limitations in this study. This was a retrospective medical record review which may have certain bias due to the nature of the study design. In addition, there was a relatively small sample size for PD patients. In order to determine the adequate sample size, we conducted a pilot study to assure statistical significance was achieved. Furthermore, we matched our patients for age and gender in a 1 to 3 ratio with non-PD patients to overcome the relatively small sample size. Another limitation is that we did not assess the clinical function and PD disease status of our patients which could provide a better overall evaluation. Finally, future studies should also include a group of PD patients that received nonoperative management after DRF to better assess the necessity of surgical fixation in this unique group.

\section{Conclusion}

In PD patients with a distal radial fracture, there was higher treatment failure rate in comparison to the nonPD group. PD patients tend to have longer hospital stays and a shorter time to treatment failure. Although internal fixation of DRF can be done with different instruments, we recommend plating of the radius over k-wire fixation for better outcomes. The treating physician must also take into account the complex disease course of PD and manage comorbidities such as osteoporosis, frail status, and unintentional tremors accordingly. Rehabilitation and disposition plans should be discussed in advance and longer hospital stays should be expected.

\section{Abbreviations}

PD: Parkinson's disease; DRF: Distal radial fractures; AAOS: American Academy of Orthopaedic Surgeons; ORIF: Open reduction and internal fixation; 
ESF: External fixator; ASA: American Society of Anesthesiologist; VAS: Visual analog scale; K-wires: Kirschner wires

\section{Acknowledgements}

We do not have acknowledgements.

\section{Authors' contributions}

Manuscript preparation: TFC, CYC, TFH. Study design: TFC, CYC, TFH. Interpretation of data: CCH, WMC, MCC. Statistical analysis: TFC, CYC, TFH. All authors read and approved the final manuscript

\section{Funding}

This study did not receive any grants or funding.

\section{Availability of data and materials}

not applicable

\section{Ethics approval and consent to participate}

This study was approved by our institutions IRB and all patients agreed to participate in this review and were consented accordingly.

\section{Consent for publication}

We agree to have this work publicized if accepted.

\section{Competing interests}

The authors do not have any competing interests.

\section{Author details}

${ }^{1}$ Department of Orthopaedics and Traumatology, Taipei Veterans General Hospital, No. 201, Sec. 2, Shi-Pai Road, Taipei 112, Taiwan, Republic of China. ${ }^{2}$ Department of Orthopaedics, School of Medicine, National Yang-Ming University, No. 201, Sec. 2, Shi-pai Road, Beitou District, Taipei City 11217, Taiwan, ROC. ${ }^{3}$ Department of Exercise and Health, National Taipei University of Nursing and Health Science, No. 201, Sec. 2, Shi-Pai Road, Taipei 112, Taiwan, Republic of China.

Received: 21 January 2020 Accepted: 20 March 2020

Published online: 31 March 2020

\section{References}

1. Cheng KY, Lin WC, Chang WN, Lin TK, Tsai NW, Huang CC, et al. Factors associated with fall-related fractures in Parkinson's disease. Parkinsonism Relat Disord. 2014;20(1):88-92. Epub 2013/10/19.

2. Genever RW, Downes TW, Medcalf P. Fracture rates in Parkinson's disease compared with age- and gender-matched controls: a retrospective cohort study. Age Ageing. 2005 Jan;34(1):21-24. Epub 2004/12/14.

3. Coomber R, Alshameeri Z, Masia AF, Mela F, Parker MJ. Hip fractures and Parkinson's disease: a case series. Injury. 2017:48(12):2730-5 Epub 2017/10/08.

4. Pouwels S, Bazelier MT, de Boer A, Weber WE, Neef C, Cooper C, et al. Risk of fracture in patients with Parkinson's disease. Osteoporos Int. 2013;24(8): 2283-2290. Epub 2013/02/23

5. Walker RW, Chaplin A, Hancock RL, Rutherford R, Gray WK. Hip fractures in people with idiopathic Parkinson's disease: incidence and outcomes. Mov Disord. 2013;28(3):334-340. Epub 2013/02/08

6. Karadsheh MS, Rodriguez EK, Harris MB, Zurakowski D, Lucas R, Weaver MJ. Mortality and revision surgery are increased in patients with Parkinson's disease and fractures of the femoral neck. Clin Orthop Relat Res. 2015; 473(10):3272-3279. Epub 2015/03/25.

7. Egol KA, Walsh M, Romo-Cardoso S, Dorsky S, Paksima N. Distal radial fractures in the elderly: operative compared with nonoperative treatment. J Bone Joint Surg Am. 2010;92(9):1851-1857. Epub 2010/08/06.

8. Diaz-Garcia RJ, Oda T, Shauver MJ, Chung KC. A systematic review of outcomes and complications of treating unstable distal radius fractures in the elderly. J Hand Surg Am. 2011;36(5):824-835 e2. Epub 2011/04/30.

9. Arora R, Gabl M, Gschwentner M, Deml C, Krappinger D, Lutz M. A comparative study of clinical and radiologic outcomes of unstable colles type distal radius fractures in patients older than 70 years: nonoperative treatment versus volar locking plating. J Orthop Trauma. 2009:23(4):237-242. Epub 2009/03/26.
10. Bezza A, Ouzzif Z, Naji H, Achemlal L, Mounach A, Nouijai M, et al. Prevalence and risk factors of osteoporosis in patients with Parkinson's disease. Rheumatol Int. 2008;28(12):1205-1209. Epub 2008/07/02.

11. Melton LJ, 3rd, Leibson CL, Achenbach SJ, Bower JH, Maraganore DM, Oberg AL, et al. Fracture risk after the diagnosis of Parkinson's disease: influence of concomitant dementia. Mov Disord. 2006;21(9):1361-1367. Epub 2006/05/17.

12. Hess DE, Carstensen SE, Moore S, Dacus AR. Smoking increases postoperative complications after distal radius fracture fixation: a review of 417 patients from a level 1 trauma center. Hand (N Y). 2018 Nov 22: 1558944718810882. Epub 2018/11/23.

13. Arora R, Lutz M, Hennerbichler A, Krappinger D, Espen D, Gabl M. Complications following internal fixation of unstable distal radius fracture with a palmar locking-plate. J Orthop Trauma. 2007;21(5):316-322. Epub 2007/05/09.

14. Prommersberger KJ, Fernandez DL. Nonunion of distal radius fractures. Clin Orthop Relat Res. 2004(419):51-56. Epub 2004/03/17.

15. Mattson JT, Louis DS. Intrapelvic migration of a threaded Steinmann pin in Parkinson's disease. Clin Orthop Relat Res. 1976 Nov-Dec(121):166-168. Epub 1976/11/01.

16. Jagodzinski M, Krettek C. Effect of mechanical stability on fracture healing-an update. Injury. 2007 Mar:38 Suppl 1:S3-10. Epub 2007/03/27.

17. Coughlin L, Templeton J. Hip fractures in patients with Parkinson's disease. Clin Orthop Relat Res. 1980(148):192-195. Epub 1980/05/01.

18. Gao H, Wei X, Liao J, Wang R, Xu J, Liu X, et al. Lower bone mineral density in patients with Parkinson's disease: a cross-sectional study from Chinese Mainland. Front Aging Neurosci. 2015;7:203. Epub 2015/11/19.

\section{Publisher's Note}

Springer Nature remains neutral with regard to jurisdictional claims in published maps and institutional affiliations.
Ready to submit your research? Choose BMC and benefit from:

- fast, convenient online submission

- thorough peer review by experienced researchers in your field

- rapid publication on acceptance

- support for research data, including large and complex data types

- gold Open Access which fosters wider collaboration and increased citations

- maximum visibility for your research: over $100 \mathrm{M}$ website views per year

At BMC, research is always in progress.

Learn more biomedcentral.com/submissions 